\title{
FORMAÇÃO PEDAGÓGICA NO CURSO DE PEDAGOGIA: INDEFINIÇÕES E DESAFIOS
}

\author{
FORMACIÓN PEDAGÓGICA EN EL CURSO DE PEDAGOGÍA: INDEFINICIONES Y \\ DESAFÍOS
}

\author{
PEDAGOGICAL FORMATION IN THE PEDAGOGY COURSE: \\ INDEFINITIONS AND CHALLENGES
}

\author{
Clara Corrêa da COSTA ${ }^{1}$ \\ Helenice Maia GONÇALVES ${ }^{2}$
}

RESUMO: Embora a literatura aponte a necessidade de repensar a formação do professor da educação básica, a formação desses profissionais vem se constituindo, ao longo de décadas, um campo de disputas de concepções. As ambiguidades, contradições e indefinições presentes na legislação vigente para a formação de professores no curso de Pedagogia refletem uma tentativa de aliar interesses distintos, sobretudo políticos e econômicos, sem que se chegue a um consenso. Assim, prevalece uma ênfase teórica à formação pedagógica, desenvolvida de forma generalista, em detrimento de conhecimentos tanto de cunho específico quanto pedagógico. A articulação desses conhecimentos, que deveria nortear a formação de professores, muitas vezes não acontece. Diante dessas considerações, este trabalho se propõe a apresentar um debate em torno da política educacional brasileira para a formação de professores no curso de Pedagogia, a fim de identificar fatores que vêm dificultando a implementação de mudanças significativas nesse curso.

PALAVRAS-CHAVE: Formação docente. Formação pedagógica. Pedagogia.

RESUMEN: Aunque el profesorado señala la necesidad de repensar la formación de los docentes de la educación básica, la formación de estos profesionales se ha constituido, a lo largo de décadas, un campo de disputas de concepciones. Las ambigüedades, contradicciones e incertidumbres presentes en la legislación actual para la formación del profesorado en el curso de Pedagogía reflejan un intento de combinar diferentes intereses, especialmente políticos y económicos, sin llegar a un consenso. Así, prevalece un énfasis teórico en la formación pedagógica, desarrollada de manera generalista, en detrimento del conocimiento, tanto de naturaleza específica como pedagógica. La articulación de estos conocimientos, que debería orientar la formación del profesorado, muchas veces no ocurre. Frente a estas consideraciones, este trabajo propone presentar un debate acerca de la política educacional brasileña para la formación del profesorado en el curso de Pedagogía, con el fin de

${ }^{1}$ Colégio Pedro II (CPII), São Cristóvão, Rio de Janeiro - RJ - Brasil. Professora do Ensino Básico Técnico e Tecnológico. Departamento de Anos Iniciais do Ensino Fundamental. Doutorado em Educação (UNESA). ORCID: https://orcid.org/0000-0003-2717-4126. E-mail: correa.clara@ outlook.com

${ }^{2}$ Universidade Estácio de Sá (UNESA), Rio de Janeiro - RJ - Brasil. Professora adjunta nível VI no Programa de Pós-Graduação em Educação. Pós-Doutorado em Psicologia da Educação (PUC/SP). ORCID: https://orcid.org/0000-0002-1169-9051.E-mail: helemaia@uol.com.br 
identificar factores que han dificultado la implementación de cambios significativos en este curso.

PALABRAS CLAVE: Formación docente. Formación pedagógica. Pedagogía.

ABSTRACT: Although the literature points to the need to rethink the formation of teachers of basic education, the formation of these professionals has been constituting, for decades, a field of disputes of conceptions. The ambiguities, contradictions and indefinitions present in the current legislation for teacher formation in the Pedagogy course reflect an attempt to combine different interests, especially political and economic ones, without reaching consensus. Thus, a theoretical emphasis on pedagogical formation prevails, developed in a generalist way, to the detriment of knowledge of specific and pedagogical nature. The articulation of this knowledge, which should guide the formation of teachers, often does not happen. Given these considerations, this paper proposes to present a debate around the Brazilian educational policy for the formation of teachers in the Pedagogy course, in order to identify factors that have been hindering the implementation of significant changes in this course.

KEYWORDS: Teacher formation. Pedagogical formation. Pedagogy.

\section{Introdução}

Apesar do avanço das discussões sobre a formação docente nas três últimas décadas, a literatura sobre o tema ainda tem apontado a precariedade da formação inicial dos professores, constantemente relacionada às fragilidades dos cursos, ao seu caráter fragmentado, ao distanciamento entre teoria e prática e entre universidade e escola de educação básica.

Consequentemente, a formação pedagógica é temática de intensos debates que buscam a superação da dicotomia entre teoria e prática, promovendo maior aprofundamento nas pesquisas que intentaram resgatar o papel do professor, pensando a formação numa abordagem que não é apenas acadêmica, mas também engloba o desenvolvimento pessoal, profissional e organizacional da profissão docente.

A formação pedagógica compreende disciplinas e práticas que, articuladas, darão ao futuro professor a base necessária para lidar, com autonomia, com as mais diversas situações que poderão surgir ao longo de sua prática docente. Embora tão cara àqueles que se dedicarão à docência e presente em documentos legais e nos intensos debates sobre a qualidade do ensino, ainda permanece em segundo plano, sendo considerada uma "atividade menor", fortalecendo a crença de que não é tão necessária.

Essa realidade afeta de maneira expressiva os licenciandos do curso de Pedagogia, que abrange a formação para o exercício da docência em diversos níveis: na educação infantil, nos 
anos iniciais do ensino fundamental, nas disciplinas pedagógicas do curso normal em nível médio, bem como na educação profissional, na área de serviços escolares, além de outras áreas nas quais são previstos conhecimentos pedagógicos, abarcando, também, o preparo para a gestão educacional, que deve integrar diversas funções, tais como administração, coordenação, planejamento, acompanhamento e avaliação de projetos pedagógicos e de políticas públicas e institucionais na área da educação (BRASIL, 2006).

Diante da grande abrangência formativa do curso e do pouco domínio dos conhecimentos da prática da profissão com o qual muitos egressos do curso de Pedagogia iniciam na carreira docente, entendemos que o atual modelo de formação ainda não constitui base de conhecimento que articula teoria e prática que orientará a atuação do futuro professor da educação infantil e dos anos iniciais do ensino fundamental, levando em conta suas especificidades.

Embora haja na literatura um consenso acerca da imprescindibilidade de alteração na estrutura do curso de Pedagogia, em que a docência constitua efetivamente o foco de atuação dos professores desse curso, essa é uma questão que ainda não foi solucionada. Por se tratar de uma dificuldade que se perpetua até os dias de hoje, em que práticas pedagógicas ainda se encontram cristalizadas, alicerçadas em um modelo tradicional de formação, é necessário promover maior discussão acerca dos fatores que vêm dificultando, atualmente, a implantação de possíveis mudanças.

É com base nessas considerações que este trabalho se propõe a apresentar um debate em torno da formação pedagógica no curso de Pedagogia, a fim de identificar possíveis fatores que vêm dificultando a implementação de mudanças significativas na formação de professores nesse curso.

\section{A criação do curso de Pedagogia}

Para a compreensão do espaço ocupado pela formação pedagógica na atual realidade do curso de Pedagogia no Brasil, cuja identidade foi se moldando ao longo da história, apresentando, ainda hoje, uma série de indefinições e desafios a serem superados, resgataremos, ainda que resumidamente, a história de sua criação.

A formação de professores passou por um longo percurso de estruturação antes da criação do curso de Pedagogia. A primeira instituição oficial destinada à formação de professores no Brasil, a Escola Normal, foi criada em Niterói, capital da Província do Rio de Janeiro, por meio de uma Carta de Lei que executou o Decreto $\mathrm{n}^{\mathbf{o}} 10$ da Assembleia 
Legislativa Provincial, de 10 de abril de 1835 (RIO DE JANEIRO, 1835). O currículo do curso era bastante escasso, constituído apenas por conteúdos disciplinares de nível primário e a única referência à metodologia de ensino se referia ao método lancasteriano ${ }^{3}$, cujos princípios teóricos e práticos seriam ensinados pelo diretor da Escola Normal.

Na mesma década, em 1837, na Província de Mato Grosso, foi proposta a criação de uma Escola Normal pela Lei $\mathrm{n}^{\circ}$ 8, de 5 de maio, que autorizava "o Governo local a contratar uma pessoa de outra localidade, devidamente capacitada" para ensinar o método lancasteriano. Em caso de não haver alguém apto, “a autoridade competente poderia, então, enviar uma pessoa da própria localidade para se instruir na Escola Normal da província do Rio de Janeiro" (XAVIER; SÁ, 2008, p. 125).

Assim, Joaquim Felicíssimo de Almeida Louzada foi enviado à Província do Rio de Janeiro para se habilitar na Escola Normal, tendo assumido a função de professor entre 1841 e 1844. Em 1844, a escola regida por ele, que habilitava professores e também funcionava como escola primária, foi fechada "por não haver um quadro de professores capacitados para o exercício do cargo, por falta de espaço físico adequado para o funcionamento da escola e por não haver verbas provinciais suficientes para a manutenção da instituição" (XAVIER; SÁ, 2008, p. 126).

Assim como a Escola Normal de Mato Grosso, a Escola Normal de Niterói também foi fechada, em 1849, por Luís Pedreira do Couto Ferraz, que, entre outros fatores, considerou que a formação proporcionada ali tinha caráter reduzido e o currículo era limitado. Após dez anos, em 1859, a Escola Normal de Niterói foi reaberta, "porém, sua implantação definitiva só se deu em 1862, quando o regulamento de 30 de abril de 1862 passou a ser executado". Em sem artigo 84, foram definidos os objetivos da Escola Normal da seguinte maneira: "a Escola Normal tem por fim habilitar na teoria e na prática, intelectual e moralmente, os cidadãos que se destinarem ao magistério da instrução primária” (CASTANHA, 2008, p. 21).

No entanto, somente a partir de 1870 as Escolas Normais passaram a apresentar algum êxito, quando se consolidaram, no Brasil, ideias de democratização e instrução primária. A formação pedagógica permanecia bastante rudimentar, composta por uma ou duas disciplinas (Pedagogia e/ou Metodologia), acrescida, em determinados casos, de legislação e administração educacional (TANURI, 2000).

${ }^{3}$ O método pedagógico de Lancaster foi escolhido pelas elites brasileiras para "a instrução elementar do povo", [...] e "se pautava pela manutenção da ordem, da disciplina e da obediência para a população livre e pobre" (NEVES, 2009, p. 62-64). 
No Rio de Janeiro, em 1879, a Reforma Leôncio de Carvalho "tentou estabelecer, no seu artigo $9^{\circ}$, uma política para a organização das Escolas Normais no Brasil, definindo um currículo mínimo" (CASTANHA, 2008, p. 27), mas com sua destituição, Francisco Maria Sodré Pereira regulamentou aquele artigo e criou uma Escola Normal de instrução primária para professores e professoras, em 1880. Com um currículo "inchado", foram necessárias alterações, e um novo regulamento estabeleceu que a finalidade da Escola Normal era preparar professores primários do $1^{\circ}$ e $2^{\circ}$ graus, compreendendo dois cursos: Ciências e Letras, e Artes.

No período de 1870 a 1880, a organização da Escola Normal enfrentava dificuldades, fosse em decorrência da situação financeira das províncias, fosse pela falta de candidatos ou pela vinculação da Escola Normal aos cursos preparatórios ao ensino superior advinda da Reforma Leôncio de Carvalho. No entanto, mesmo nesse contexto, ao final do Império, praticamente todas as províncias tinham uma Escola Normal.

A partir da década de 1920, o movimento escolanovista passou a exercer forte influência sobre a organização do ensino, apoiando ideias de flexibilização que buscavam adaptar os programas ao desenvolvimento e à individualidade do educando, entre outras "iniciativas, quase que totalmente vinculadas à formação do professor primário e, portanto, deram-se no âmbito da Escola Normal" (KULESZA, 2002, p. 6). Mais ainda, "metade dos "pioneiros" - na verdade os que mais contribuíram, por suas ideias e atuação, para erigir o Manifesto em documento histórico fundamental do escolanovismo e da educação brasileira estavam visceralmente ligados às Escolas Normais" (idem, p. 9). Conforme continua expondo Kulesza (2002, p. 6), “as Escolas Normais foram, desde 1870 até meados da década de 1930, o campo de experimentação e difusão por excelência da renovação educacional no Brasil", sendo a "grande artífice desta verdadeira revolução cultural em solo brasileiro".

Num contexto de busca pela remodelação do ensino, foi criado, por Getúlio Vargas, em 1930, o Ministério da Educação e Saúde Pública por meio do Decreto no 19.402 , de 14 de novembro de 1930. Seu primeiro titular, Francisco Campos, aprovou o Estatuto das Universidades Brasileiras, o qual ficou em vigor até 1961. De acordo com esse conjunto de regulamento, as universidades poderiam ser públicas ou particulares e deveriam incluir três dos seguintes cursos: Direito, Medicina, Engenharia, Educação, Ciências e Letras (OLIVEN, 2002).

Francisco Campos regulamentou uma série de decretos que ficaram conhecidos como Reforma Francisco Campos e que "forneceram uma estrutura orgânica ao ensino secundário, comercial e superior; pela primeira vez na história da educação brasileira, uma reforma que se 
aplicava a vários níveis de ensino e objetivava alcançar o País como um todo" (MORAES, 1992, p. 293). Uma série de medidas foi, então, afixada, tais como o aumento de anos para a formação do aluno no curso secundário; a seriação do currículo do curso e a sua divisão em dois ciclos; a frequência obrigatória dos estudantes às aulas; e a implantação de um sistema de avaliação discente regular e mais detalhado. Tais medidas buscavam atender às demandas da sociedade capitalista da época (DALLABRIDA, 2009).

O país passou a demandar, cada vez mais, mão de obra qualificada às novas funções de gerência e serviços especializados e a reivindicar do Estado ações educacionais que garantissem a formação de pessoal capacitado para ocupar tais funções. Assim, a expansão da escolarização passa a ser, também, de interesse capitalista (TANURI, 2000; SILVA, 2004; SCHEIBE; DURLI, 2011) e “educar a população, urbana e também rural, pareceu condição primeira para que se consolidasse a economia capitalista industrial e fosse garantido o desenvolvimento do País. O ensino seria exigência a todo trabalhador, que deveria adquirir um mínimo de instrução" (SANTOS; PRESTES; VALE, 2006, p. 136). Paralelamente, o movimento dos educadores ganhava força e, como registra Andreotti (2008, p. 2), "os anos 1930 foram férteis em relação à nova educação, defendida por educadores que ocuparam cargos na administração pública e que implementaram diretrizes educacionais, respaldados por essa visão de educação".

Em 1937, foi criado o Instituto Nacional de Pedagogia, iniciando efetivamente seus trabalhos em 1938, quando passou a ser conhecido como Instituto Nacional de Estudos Pedagógicos (INEP). O instituto oferecia cursos para os diversos cargos de administração escolar, contemplando as demandas de qualificação de pessoal (TANURI, 2000). No ano seguinte, em 1939, foi instituído, pelo Decreto-Lei n 1190 , o curso de Pedagogia, criado pela Faculdade de Filosofia, Ciências e Letras para atender aos ditames de uma proposta de formação universitária profissionalizante. Sua criação foi consequência da preocupação com a formação de docentes para atuarem no curso normal (MARTELLI; MANCHOPE, 2004).

O curso apresentava duas finalidades centrais: formar, mediante a titulação de bacharel, técnicos em educação, especializados em questões burocráticas dos sistemas de ensino, e formar professores para atuar nas Escolas Normais e em algumas disciplinas do secundário, mediante titulação de licenciado. A titulação de bacharel era alcançada após três anos de estudos dos fundamentos da educação e a de licenciado era dada em acréscimo, de caráter facultativo, com duração de um ano, compreendendo o curso de didática (BRASIL, 1939). 
Esse modelo de formação, em que a habilitação do professor para o exercício do magistério se dá como um adendo do curso de bacharelado, ficou conhecido como " $3+1$ ", marcando o início de um longo período de dissociação entre teorias educacionais e práticas pedagógicas.

O curso de Pedagogia, assim como as demais licenciaturas, concentrava-se, primeiramente, no estudo dos conteúdos específicos relacionados ao bacharelado e, depois, realizava-se o estudo dos conteúdos pedagógicos no curso de didática. Brzezinski (2015) sinaliza, entretanto, que o mercado de trabalho para o bacharel em Pedagogia, que se formava técnico em educação, nunca fora precisamente definido. Portanto, segundo ela, o curso, em seus períodos iniciais, buscava um específico inexistente, constituído de generalidades sobre ciências auxiliares da Pedagogia. Assim, o bacharelado em Pedagogia seguia em caminho oposto aos demais bacharelados.

É importante ressaltar que a licenciatura em Pedagogia, tal como foi implantada em 1939, tinha como objetivo formar os professores que atuariam na Escola Normal, os quais formariam professores primários. No entanto, os conteúdos do curso primário não eram contemplados no currículo dessa licenciatura, o que, conforme aponta Brzezinski (2015, p. 46), disseminou o discurso de que "quem pode o mais pode o menos". A falta de conteúdo específico no curso de Pedagogia, que não se desenvolvia nos períodos iniciais do curso pelo motivo anteriormente mencionado, diferentemente do que acontecia nos demais cursos de licenciatura, passou a ser um dificultador que conduziu a distorções em relação à sua função.

Em 1946, houve uma tentativa de substituir o modelo " $3+1$ ”, passando o curso a ter a obrigatoriedade de quatro anos. Os três primeiros anos eram compostos por disciplinas fixas e obrigatórias e, no quarto, o aluno poderia optar por cursar disciplinas optativas ou didática teórica e prática (SCHEIBE; DURLI, 2011). No entanto, o modelo que pretendia superar o tradicional “ $3+1$ ” constituiu apenas uma forma de reiterá-lo, pois a titulação continuava dissociada.

No mesmo ano, em decorrência dos pensamentos pedagógicos de movimentos educacionais que visavam à melhoria da educação, o então Ministro da Educação e Saúde, Clemente Mariani, nomeou uma comissão de educadores notáveis com a finalidade de apresentar um anteprojeto de reforma geral da educação nacional (TANURI, 2000; SCHEIBE; DURLI, 2011).

Após 13 anos de disputas "entre os interesses confessionais e privatistas em educação e a visão republicana da escola democrática, laica e gratuita" (AZANHA, 1999, p. 167), o projeto consolidou-se, em 1961, na primeira Lei de Diretrizes e Bases da Educação, Lei no 
4.024 (BRASIL, 1961), tendo como principal bandeira a democratização do ensino e a defesa da escola pública.

O capítulo IV desta lei versa sobre a formação do magistério para o ensino primário e édio, definindo que "a formação de professores, orientadores, supervisores e administradores escolares destinados ao ensino primário e o desenvolvimento dos conhecimentos técnicos relativos à educação da infância" é competência do ensino normal, e será realizada durante, no mínimo, quatro anos, “em escola normal de grau ginasial” (BRASIL, 1961, Art. 52).

Em meados da década de 1960, o país viveu um momento em que os princípios da eficiência, produtividade e racionalidade passaram a reordenar o processo educativo. Dessa forma, procurava-se tornar a escola mais produtiva, eficiente e operacional, pensando-se a formação para o trabalho. Acentuava-se, cada vez mais, uma visão tecnicista, valorizando-se a divisão do trabalho, buscando atender às peculiaridades do mercado de trabalho (TANURI, 2000; SCHEIBE; DURLI, 2011; BRZEZINSKI, 2015).

Em 1968, foi implantada a Lei da Reforma Universitária, Lei n. 5.540 (BRASIL, 1968), que estabeleceu as normas de organização e funcionamento do ensino superior. O curso de Pedagogia deixou de integrar as Faculdades de Filosofia e passou a ser oferecido pelas Faculdades de Educação. A Lei propunha diferentes habilitações ao curso de Pedagogia, dentre as quais os estudantes optariam pela que desejasse seguir em sua carreira, sendo elas: Magistério no Ensino Normal, Administração Escolar, Supervisão de Ensino, Orientação Escolar e Inspeção Escolar, possibilitando, também, o magistério nos anos iniciais de escolaridade, mediante estudo de Metodologia e Prática de Ensino durante o percurso formativo. Manteve-se o currículo mínimo, com uma parte comum ao curso e outra parte diversificada, de acordo com a habilitação elegida pelo estudante.

Scheibe e Durli (2011) ressaltam que houve discordância em relação à titulação a ser concedida aos egressos do curso de Pedagogia em sua nova configuração. Segundo as autoras, o relator dos documentos, Valnir Chagas, defendia a titulação somente de bacharel. No entanto, considerando o egresso um especialista que recebeu formação para a docência, o plenário do Conselho Federal de Educação (CFE) optou por conferir o título único de licenciado.

Cabe ressaltar que a base curricular comum do curso contemplava as mesmas disciplinas do antigo bacharelado, proposto pela legislação de 1962. Portanto, era mantido um modelo fragmentado, embora com uma nova roupagem. A formação nos moldes do esquema “3+1”, anteriormente complementada por disciplinas pedagógicas, propiciando a titulação de 
licenciado, passa, então, a ser complementada por disciplinas que visam habilitar diferentes especialistas em assuntos educacionais.

A legislação, que até então se apresentava de forma mais geral, mencionando a formação do "técnico em educação", torna-se mais clara no que diz respeito ao profissional que se pretende formar e a seu campo de atuação. No entanto, o curso vai perdendo a identidade docente, tornando-se cada vez mais central a identidade de especialista, com base no tecnicismo.

A década de 1980 a 1990 foi marcada por mobilizações de educadores com a intenção de intervir nas políticas de reformulação dos cursos de formação de professores. Inúmeras críticas emergiram em relação à legislação para o curso de Pedagogia com a proposta de habilitações distintas, em relação ao seu caráter teórico e generalista, à fragmentação da formação, à divisão do trabalho no meio educacional e à ruptura entre teoria e prática. No entanto, a legislação manteve-se vigente por três décadas, até a aprovação, em 1996, da Lei de Diretrizes e Bases da Educação Nacional (LDBEN).

A década de 1990 foi marcada por uma tendência neoliberal, acentuando-se uma racionalidade técnica de formação, o que fez com que a profissão docente estivesse em posição de desvalorização social, tendo a qualidade do ensino sofrido drásticas consequências em todos os níveis. Nesse contexto, desconsiderando toda a trajetória do curso de Pedagogia no sentido dos avanços conquistados em direção à adoção do modelo de formação docente para os anos iniciais de escolarização em nível superior, ficou estabelecido pela referida Lei "a formação de profissionais de educação para administração, planejamento, inspeção, supervisão e orientação educacional para a educação básica” (BRASIL, 1996, Art. 64).

Reiterou-se o caráter tecnicista do curso, na condição de bacharelado profissionalizante, estabelecendo-se a formação de especialista em gestão administrativa e coordenação pedagógica. Nenhuma menção foi feita, no documento, ao curso de Pedagogia como local de formação do professor. Para tal, a LDBEN anunciava uma nova instituição no cenário educacional, o Instituto Superior de Educação (ISE), sendo indicado como local preferencial para a formação de professores para a educação infantil e os anos iniciais do ensino fundamental. No entanto, admitir-se-ia "como formação mínima para o exercício do magistério na educação infantil e nas quatro primeiras séries do ensino fundamental a oferecida em nível médio na modalidade normal (BRASIL, 1996, Art. 62).

A LDBEN gerou uma série de indefinições e ambiguidades, as quais foram alvo de críticas dos movimentos de educadores, o que intensificou os debates acerca da formação docente a partir de sua implantação. 
Apesar da intenção de elevar a formação docente a nível superior, a LBDEN admitia, como formação mínima para o exercício do magistério, aquela realizada em nível médio, na modalidade Normal. Entretanto, ficou instituído a Década da Educação, que estipulava o prazo de 10 anos, a contar a partir de um ano após a sua publicação, para que somente fossem admitidos "professores habilitados em nível superior ou formados por treinamento em serviço" (BRASIL, 1996, Art. 87).

Em 2013, por meio da Lei ${ }^{\circ} 12.796$ (BRASIL, 2013), o Artigo 87, que anteriormente estipulava o prazo para a extinção daquele curso, foi vetado, reiterando-se a formação em nível médio para atuação na educação infantil e nos anos iniciais do ensino fundamental, ainda que admitida como formação mínima, o que foi corroborado por sua outra atualização, em 2017, por meio da Lei $n^{\circ} 13.415$ (BRASIL, 2017), mantendo-se ainda vigente.

A forma como a legislação para a formação de professores foi se constituindo evidencia que a manutenção da formação no curso normal, em nível médio, até os dias de hoje tenha se dado não por uma questão de planejamento, mas pelos resultados negativos obtidos a partir da LDBEN. Não sendo possível criar condições, dentro da realidade brasileira, para que a formação de professores se desse exclusivamente em nível superior no prazo determinado pela referida Lei, optou-se por legalizar a manutenção dessa formação em nível médio. Assim, até hoje, mantém-se essa formação em vários estados do Brasil, inclusive nos mais desenvolvidos, como o Rio de Janeiro.

Após um período intenso de debates, em que educadores defendiam uma formação ampla da docência a ser realizada no Ensino Superior, devendo ocorrer no curso de Pedagogia, o CNE/CP aprovou, em 2006, a Resolução nº 1 (BRASIL, 2006) com as Diretrizes Curriculares para o curso de Pedagogia (DCN). O documento propõe, em seu Artigo $2^{\circ}$, a formação em licenciatura para o exercício da docência na educação infantil, nos anos iniciais do ensino fundamental, nos cursos de ensino médio, na modalidade normal, em cursos de educação profissional na área de serviços e apoio escolar, assim como em outras áreas nas quais sejam previstos conhecimentos pedagógicos.

O documento reconhece a docência como centro da formação no curso de Pedagogia. A antiga formação do especialista em educação é extinta, passando-se a considerar o professor como protagonista dos processos educacionais, incluindo-se, em suas competências, a participação na organização e na gestão de sistemas e instituições de ensino. O documento propõe, portanto, uma ampliação do conceito de docência.

Cabe ressaltar que o próprio conceito de gestão aparece no documento de maneira ressignificada, abrangendo a gestão administrativa e pedagógica. Além disso, as atividades 
relativas à pesquisa se encontram no interior das tarefas de gestão, enumeradas pelo documento. A pesquisa assume, portanto, um papel secundário, sendo vista como um adendo à gestão.

Entendemos que a sobrecarga de ênfases formativas propostas pelas DCN, por meio da ampliação do conceito de docência, confere ao curso de Pedagogia um caráter fragmentado, reduzindo-se às possibilidades de abordagens teórico-práticas. Embora o documento tenha destituído as diferentes habilitações do curso, passando a oferecer uma formação única, com foco na docência, direta ou indiretamente, a formação para as funções que as diferentes habilitações se propunham a formar permanece. Ao propor um conceito mais amplo de docência, o documento sobrecarrega a formação inicial no curso, sem que a problemática da fragmentação tenha sido solucionada.

Embora grande parte dos estudos aponte a necessidade de repensar a formação do professor da educação básica, é preciso ressaltar que a formação desses profissionais vem se constituindo, ao longo de décadas, um campo de disputas de concepções. As ambiguidades, contradições e indefinições presentes na legislação em vigor para a formação de professores no curso de Pedagogia refletem uma tentativa de aliar interesses distintos em relação à formação de professores, sem que se chegue a um consenso.

A imensa complexidade que compõe a legislação gerou ainda mais tensões e conflitos entre os educadores, que assumiram posicionamentos diferentes em relação à identidade do curso de Pedagogia, o que focalizaremos a seguir.

\section{A identidade do curso de Pedagogia em questão}

A identidade do curso de Pedagogia é uma questão que vem sendo fortemente discutida desde antes de sua criação, em 1939, pela dificuldade em se definir as funções do curso e, consequentemente, o campo de atuação profissional de seus egressos. O modelo " $3+1$ " foi marcado pela falta de definição da identidade do profissional que se pretendia formar, tanto no que se refere ao bacharelado quanto à licenciatura.

As décadas subsequentes à criação do curso de Pedagogia foram marcadas por longos e intensos debates sobre a formação de professores, que se acentuaram nos anos de 1990. A publicação da LDBEN, em 1996, elevando a nível superior a formação de professores para atuarem na educação infantil e na primeira etapa do ensino fundamental e, posteriormente, as DCN de 2006, que apresentaram uma concepção ampliada do conceito de docência, intensificaram o debate acerca da identidade do curso de pedagogia. 
A discussão centrava-se, essencialmente, no que diz respeito às suas finalidades: a de formar professores, especialistas em assuntos educacionais ou ambos os profissionais. $\mathrm{Na}$ literatura sobre formação no curso de Pedagogia, evidenciam-se duas posições distintas: uma que compreende a docência, em seu amplo conceito, como base da formação no curso de Pedagogia e outra que valoriza a formação técnica, científica e teórica, considerando a docência como uma das funções educativas.

A Associação Nacional pela Formação dos Profissionais em Educação (ANFOPE), desde a sua criação, em 1990, assumiu fortemente a posição de que a docência deveria constituir a essência do curso de Pedagogia. É válido ressaltar, no entanto, que a docência é vista por seus associados em seu sentido amplo, compreendendo não apenas o preparo para a função do professor, mas, também, para as funções do "pedagogo", as quais compreendem gestão administrativa, coordenação pedagógica e pesquisa.

O conceito de docência, tal como defendido pela ANFOPE, vai, pois, além da função do ensino na atuação imediata relacionada à sala de aula, englobando as funções de professor, gestor e pesquisador. Tal premissa é defendida por pesquisadores como Helena de Freitas, Iria Brzezinski, Leda Scheibe, Lucilia Lino, Marcia Ângela Aguiar, Vera Lucia Bazzo e Zenilde Durli.

Partindo de outro entendimento em relação ao papel da docência, outros pesquisadores assumem posição distinta da defendida pela ANFOPE e seus associados. Entre eles, encontram-se José Carlos Libâneo, Selma Garrido Pimenta e Maria Amélia Franco, que evidenciam a preocupação com o oferecimento de uma formação técnica, científica e teórica capaz de dar conta da formação do professor, do gestor e do pesquisador, sem que a sua formação seja resumida às habilidades docentes.

De acordo com as orientações das DCN (BRASIL, 2006), a docência constitui a base da formação no curso de Pedagogia, que é denominado como licenciatura, devendo ser assegurada a articulação entre a docência, a gestão e a produção de conhecimento. É possível afirmar que o documento incorporou fundamentalmente a concepção de identidade do curso de Pedagogia cunhada pela ANFOPE, sendo alvo de críticas de pesquisadores que mantinham posição divergente.

Levando em conta a - ainda atual - demanda de maior articulação entre as teorias e práticas desenvolvidas no curso de Pedagogia, entendemos que é possível que a proposta da ANFOPE esteja mais próxima de atender, ainda que não integralmente, às necessidades da formação de professores, por procurar formar protagonistas do processo de ensino e aprendizagem (o professor) por meio de uma base comum, o que lhes possibilitará, também, 
desenvolver, de forma articulada, ao longo do curso, habilidades para exercer as funções de gestão e para a produção de conhecimento por meio da pesquisa.

A história do curso de Pedagogia foi marcada por uma série de questionamentos, conflitos e impasses no que se refere à sua identidade, na tentativa de reorganização do curso de forma que ele proporcionasse a formação com base nas demandas da sociedade. Os impasses ainda hoje identificados constituem evidências de que ainda há muito o que fazer.

Considerando a complexidade no que diz respeito à identidade do profissional formado nos cursos de Pedagogia, ocasionada pelas indefinições em relação ao campo de atuação desse profissional e pelas prioridades estabelecidas pelas universidades, entendemos que a formação pedagógica acabou não recebendo a devida atenção.

\section{Formação pedagógica no curso de Pedagogia: o que o cenário atual revela}

O cenário atual da educação brasileira nos leva a concluir que a elevação da formação docente a nível superior não garantiu a sua qualidade. Nesse sentido, Santos (2013, p. 71) aponta a necessidade de pensar um modelo de formação que "responda, de fato, às demandas da atuação profissional do professor, corporificadas nos desafios da educação brasileira hoje”.

A LDBEN, publicada em 1996, tida como referência central para a educação brasileira, continua em curso, embora tenha sofrido significativas alterações ao longo de mais de duas décadas de sua implantação. As instituições vêm se adaptando lentamente a ela, havendo, ainda, certa resistência, especialmente por parte das universidades públicas, em que o apego à tradição histórica se apresenta como uma característica bem acentuada (CRUZ, 2008; CORRÊA, 2015).

De acordo com Brzezinski (2014), ao analisar o histórico das alterações feitas na LDBEN, a expressiva quantidade de intervenções em seu texto base evidencia, por um lado, a continuidade do debate em torno da problemática educacional brasileira sem, contudo, deixar de revelar contradições e embates que envolvem educadores que buscam a melhoria da qualidade da Educação. Por outro lado, confirma a tendência do sistema educacional de atuar de forma fragmentada, em que decisões são tomadas de forma apressada, "atreladas às determinações casuísticas de programas gestionários de governança e de implementação de políticas públicas voltadas para interesses e objetivos imediatistas, que se busca legitimar pela inclusão no texto legal" (BRZEZINSKI, 2014, p. 30).

Alves-Mazzotti (2011, p. 292) define, resumidamente, a normatização relativa à formação de professores como "um emaranhado de diretrizes, resoluções, portarias, pareceres 
que mais confundem do que esclarecem gestores e professores responsáveis por sua implementação a respeito do que e como fazer". Ou seja, fica evidenciado que a legislação relativa à formação de professores, efetivada de maneira segmentada, fruto de negociações de interesses, sobretudo, políticos e econômicos, constitui elemento dificultador na efetivação de mudanças nos currículos dos cursos de Pedagogia.

As imprecisões da legislação justificam, em parte, a forma desordenada com que a formação vem se efetivando na prática nas instituições de ensino das diferentes instâncias. Embora saibamos que a legislação por si só não garante a sua implantação e a qualidade da formação docente, não deixa de ser a base para que propostas surjam no sentido de promover mudanças. A ausência de continuidade com a qual a legislação brasileira para a formação de professores foi sendo implantada, suas contradições e ambiguidades vêm dificultando ainda mais a concretização de ações em direção à evolução dos processos de formação docente.

A ampla complexidade curricular exigida para o curso de Pedagogia também se constitui como um grande desafio a ser enfrentado pelas instituições de ensino. Autores como Gatti et al., (2019) questionam a viabilidade de tempo para se constituir uma formação que dê conta de todas as especificidades propostas pela LDBEN considerando as peculiaridades da docência na educação infantil, nos anos iniciais do ensino fundamental, do gestor e do pesquisador. Além disso, apontam as características dos currículos dos cursos, que atualmente mantém uma proposta de formação panorâmica e fragmentada, outro elemento que dificulta a efetivação de uma formação sólida.

Para além das características da legislação, outro elemento interfere de maneira significativa na efetivação de mudanças na realidade social na qual é desenvolvida a formação de professores: a tradição do antigo bacharelado, ainda bastante presente na prática de docentes formadores de professores nas licenciaturas.

Em relação a essa questão, Gatti (2014, p. 36) sinaliza a necessidade de "superar conceitos arraigados e hábitos perpetuados secularmente e ter condições de inovar”. No entanto, sinaliza que essa é uma tarefa bastante desafiadora quando se tem "uma cultura acadêmica acomodada", aliada a interesses diversificados de grandes instâncias.

Em relação ao atual modelo de formação dos cursos de licenciatura, Scheibe e Bazzo (2016) acreditam que haja certo "sombreamento", permanecendo-se, na prática, a licenciatura como um apêndice ao bacharelado, nos moldes do antigo modelo " $3+1$ ”. Embora questionado e atenuado pela legislação, as autoras apontam que este modelo está presente na cultura pedagógica de formação de professores, ainda calcada na separação entre teoria e prática. 
É válido ressaltar que quando associamos, atualmente, o modelo " $3+1$ " aos cursos de licenciatura em áreas específicas do conhecimento, nos referimos a uma formação que prioriza a área de atuação docente (como Matemática, Língua Portuguesa, Biologia, História, Geografia), adicionando-se a ela a formação pedagógica, o que reforça a dicotomia entre os conteúdos disciplinares e a formação pedagógica.

Quando nos referimos ao curso de Pedagogia, percebemos outro cenário, ainda mais preocupante. Há supervalorização das teorias pedagógicas, desenvolvidas de maneira generalista, em detrimento dos conhecimentos específicos que os professores estarão aptos a lecionar e dos conhecimentos pedagógicos aplicados a eles. É dada ênfase teórica à formação pedagógica. Acerca dessa fragilidade do curso de Pedagogia para o efetivo exercício da docência, Gatti (2014) aponta que há uma deficiência formativa em relação aos conteúdos específicos das diferentes áreas a serem ministrados, além de um espaço bastante reduzido para o desenvolvimento de habilidades pedagógicas específicas para a atuação do futuro professor. Segundo a autora, há maior preocupação com o oferecimento de teorias como forma de contextualizar os desafios do trabalho, o que ela considera abstratas.

Em investigação sobre o exercício da docência, Maia (2019) evidencia o despreparo dos professores formados pelo curso de Pedagogia para lidarem com o cotidiano escolar e a falta de familiaridade com os conteúdos a serem ensinados. Estudos apontam que essas dificuldades decorrem da formação pedagógica deficiente, distanciada da realidade da sala de aula, com pouca atividade destinada ao exercício da prática pedagógica.

Considerando a supervalorização das teorias pedagógicas, desenvolvidas de maneira generalista no curso de Pedagogia, em detrimento dos conhecimentos específicos e, também, dos conhecimentos pedagógicos, prevalecendo a ênfase teórica à formação pedagógica, mantem-se a dicotomia entre teoria e prática, o que se agrava ainda mais no caso desse curso, considerando que a docência deve abranger a gestão administrativa e pedagógica do espaço escolar.

\section{Considerações finais}

Com base no histórico do curso de Pedagogia e considerando o seu panorama atual, conforme apresentado neste trabalho, pode-se dizer que há diversos elementos que dificultam o desenvolvimento de uma formação pedagógica no curso de Pedagogia que dê ao futuro professor a base necessária para lidar, com autonomia, com os desafios que poderão surgir ao longo de sua prática docente. 
Entre eles, destacamos a maneira segmentada como a legislação para a formação de professores foi sendo implantada; as características dos currículos dos cursos, que mantêm uma formação panorâmica, em função da ampla complexidade curricular exigida para o curso e a viabilidade de tempo necessário para o seu desenvolvimento; e o apego à tradição do antigo bacharelado, presente na prática de professores de curso de Pedagogia.

Assim, prevalece uma ênfase teórica à formação pedagógica, desenvolvida de forma generalista, em detrimento de conhecimentos tanto de cunho específico quanto pedagógico. A articulação desses conhecimentos, que deveria nortear a formação de professores, muitas vezes não acontece.

Embora ainda estejamos diante de um cenário pouco otimista, é mister prosseguir na busca pela melhoria da formação no curso de Pedagogia, em especial, no que se refere à formação pedagógica dos futuros professores. Associações como a ANFOPE, que, ao longo de toda a história de sua criação, lutam por esse ideal, nos fazem crer que a mudança é possível se não nos deixarmos levar pelo discurso da dificuldade, que vem, há tanto tempo, reforçando o imobilismo, fruto do apego à tradição.

\section{REFERÊNCIAS}

ALVES-MAZZOTTI, A. J. Formação para o magistério: o discurso dos formadores. Revista Diálogo Educacional, Curitiba, v. 11, n.33, p. 287-307, maio/ago. 2011. Disponível em: http://www2.pucpr.br/reol/pb/index.php/dialogo. Acesso em: 06 mar. 2020.

\section{ANDREOTTI, A. L. O governo Vargas e o equilíbrio entre a pedagogia tradicional e a pedagogia nova. Disponível em:}

http://www.histedbr.fe.unicamp.br/navegando/periodo_era_vargas_intro.html. Acesso em: 17 mar. 2020.

AZANHA, J. M. P. Roque Spencer Maciel de Barros: defensor da escola pública. Educação e Pesquisa, São Paulo, v. 25, n. 1, p. 167-169, jan./jun. 1999. Disponível em: http://www.scielo.br/pdf/ep/v25n1/v25n1a13.pdf. Acesso em: 11 maio 2020.

BRASIL. Conselho Nacional de Educação. Resolução CNE/CP n. 1/2006, de 15 de maio de 2006. Institui Diretrizes Curriculares Nacionais para o Curso de Graduação em Pedagogia, licenciatura. Diário Oficial da União, Brasília, DF, 16 maio 2006. Disponível em: http://portal.mec.gov.br/cne/arquivos/pdf/rcp01_06.pdf. Acesso em: 22 abr. 2020.

BRASIL. Decreto-Lei n. 1.190, de 4 de abril de 1939. Organização da Faculdade Nacional de Filosofia. Diário Oficial da União, Brasília, DF, 6 abr. 1939. Seção 1, p. 7.929. Disponível em: https://www2.camara.leg.br/legin/fed/declei/1930-1939. Acesso em: 12 abr. 2020.

BRASIL. Ministério da Educação. Lei n. 4.024, de 20 de dezembro de 1961. Estabelece as diretrizes e bases da educação nacional. Diário Oficial da União, Brasília, DF, 27 dez. 1961. 
Disponível em: http://www.planalto.gov.br/ccivil_03/leis/L4024.htm. Acesso em 12 maio 2020.

BRASIL. Ministério da Educação. Lei n. 5.540, de 28 de novembro de 1968. Fixa normas de organização e funcionamento do Ensino Superior e sua articulação com a escola média e dá outras providências. Ministério da Educação. Diário Oficial da União, Brasília, DF, 23 nov. 1968. Disponível em: http://www.planalto.gov.br/ccivil_03/leis/L5540.htm. Acesso em: 12 abr. 2020.

BRASIL. Ministério da Educação. Lei n. 9.394, de 20 de dezembro de 1996. Estabelece as diretrizes e bases da educação nacional. Diário Oficial da União, Brasília, DF, 23 dez. 1996. Disponível em: http://www.planalto.gov.br/ccivil_03/leis/19394.htm. Acesso em: 13 maio 2020.

BRASIL. Ministério da Educação. Lei n. 12.796, de 04 abril de 2013. Altera a Lei nº 9.394, de 20 de dezembro de 1996, que estabelece as diretrizes e bases da educação nacional, para dispor sobre a formação dos profissionais da educação e dar outras providências. Diário Oficial da União, Brasília, DF, 5 abr. 2013. Disponível em:

http://www.planalto.gov.br/ccivil_03/_Ato2011-

2014/2013/Lei/L12796.htm\#: :text=LEI\%20N\%C2\%BA\%2012.796\%2C\%20DE\%204\%20D E\%20ABRIL\%20DE\% 202013.\&text=Altera\%20a\%20Lei\%20n\%C2\%BA\%209.394,educa\% C3\%A7\%C3\%A3o\%20e\%20dar\%20outras\%20provid\%C3\%AAncias. Acesso em: 13 maio 2020.

BRASIL. Ministério da Educação. Lei n. 13.415 de 16 de fevereiro de 2017. Altera a Lei ${ }^{\circ}$ 9394 de 20 de dezembro de 1996, que estabelece as diretrizes e bases da educação nacional, para dispor sobre a formação dos profissionais da educação e dar outras providências. Diário Oficial da União, Brasília, DF, 17 fev. 2017. Disponível em: http://www.planalto.gov.br/ccivil_03/_ato2015-2018/2017/lei/L13415.htm. Acesso em: 10 maio 2020.

BRZEZINSKI, I. LDB/1996 Contemporânea: contradições, tensões, compromissos. São Paulo: Cortez, 2014.

BRZEZINSKI, I. Pedagogia, pedagogos e formação de professores: busca e movimentos. São Paulo: Papirus, 2015.

CASTANHA, A. P. Escolas Normais no século XIX: um estudo comparativo. Revista HISTEDBR On-line, Campinas, n. 32, p.17-36, dez. 2008. Disponível em: https://www.fe.unicamp.br/pf-fe/publicacao/5395/art02_32.pdf. Acesso em: 06 maio 2020.

CRUZ, G. B. O Curso de Pedagogia no Brasil na visão de pedagogos primordiais. 2008. 305 f. Tese (Doutorado em Educação). Pontifícia Universidade Católica do Rio de Janeiro. 2008.

DALLABRIDA, N. A Reforma Francisco Campos e a modernização nacionalizada do ensino secundário. Educação, Porto Alegre, v. 32, n. 2, p. 185-191, maio/ago. 2009. Disponível em: http://revistaseletronicas.pucrs.br. Acesso em: 20 abr. 2020.

GATTI, B. A. A formação inicial de professores para a educação básica: as licenciaturas. 
Revista USP, São Paulo, n. 100, p. 33-46, dez./jan./fev. 2014. Disponível em: http://www.revistas.usp.br/revusp/article/view/76164. Acesso em: 28 abr. 2020.

GATTI, B. A et al. A. Professores do Brasil: novos cenários de formação. Brasília: UNESCO, 2019.

KULESZA, W. A. Genealogia da Escola Nova no Brasil. Revista Educação em Foco, Juiz de Fora, v. 7, n. 2, p. 83-92, set./fev. 2002. Disponível em:

http://www.ufjf.br/revistaedufoco/files/2010/02/061.pdf. Acesso em: 15 maio 2020.

MAIA, H. Formação docente em nível médio e superior: perspectivas de professores sobre o exercício da docência em seu trabalho. Revista Internacional de Formação de Professores (RIFP), Itapetininga, v. 4, n. 2, p. 149-168, abr./jun. 2019. Disponível em:

https://periodicos.itp.ifsp.edu.br/index.php/RIFP/article/view/1417/1038. Acesso em: 15 maio 2020.

MARTELLI, A. C.; MANCHOPE, E. C. P. A história do curso de Pedagogia no Brasil: da sua criação ao contexto após LDB 9394/96. Revista Eletrônica de Ciências da Educação, v. 3, n. 1, p. 1-21, 2004. Disponível em: http://www.periodicosibepes.org.br/index.php. Acesso em: 15 maio 2020.

MORAES, M. C. M. Educação e Política nos Anos 30: a Presença de Francisco Campos. Revista Brasileira de Estudos Pedagógicos, Brasília, v. 73, n. 17-4, p. 291-321, maio/ago. 1992. Disponível em: http://emaberto.inep.gov.br/index.php/rbep/article/view/1257. Acesso em: 15 maio 2020.

NEVES, F. M. O método pedagógico de Lancaster e a instituição do estado nacional brasileiro. In: ROSSI, E. R.; RODRIGUES, E.; NEVES, F. M. (Org.). Fundamentos históricos da educação no Brasil. Maringá: UEM, 2009, p.57-66.

OLIVEN, A. C. Histórico da Educação Superior no Brasil. In: SOARES, M. S. A. (Org.). A Educação Superior no Brasil. Brasília: Coordenação de Aperfeiçoamento de Pessoal de Nível Superior (CAPES), 2002.

RIO DE JANEIRO. Decreto $\mathbf{N}^{\mathbf{0}} \mathbf{1 . 3 3 1 - A}$, de 17 de fevereiro de 1854. Aprova o regulamento para a reforma do ensino primário e secundário do Município da Côrte. Disponível em: https://www2.camara.leg.br/legin/fed/decret/1824-1899/decreto-1331-a-17-fevereiro-1854-590146publicacaooriginal-115292-pe.html. Acesso em: 09 maio 2020.

SANTOS, I. M. A formação de professores e o curso de Pedagogia, Debates em Educação, Maceió, v. 5, n. 9, p. 67-78, jan./jun. 2013. Disponível em: www.seer.ufal.br/index.php/debateseducacao. Acesso em: 16 maio 2020.

SCHEIBE, L; DURLI, L. Curso de Pedagogia no Brasil: olhando o passado, compreendendo o presente. Revista Educação em Foco, ano 14, n. 17, p. 79-109, jul. 2011. Disponível em: revista.uemg.br/index.php/educacaoemfoco/article/view/104. Acesso em: 13 mar. 2020.

TANURI, L. M. História da formação de professores. Revista Brasileira de Educação, Rio de Janeiro, n. 14, p. 61-88, maio/ago. 2000. Disponível em:

www.scielo.br/pdf/rbedu/n14/n14a. Acesso em: 12 mar. 2020. 
XAVIER, A. P. S.; SÁ, N. P. A escola normal de Mato Grosso no século XIX. Série-Estudos Periódico do Mestrado em Educação da UCDB, Campo Grande-MS, n. 25, p. 123-132, jan./jun. 2008. Disponível em: http://www.serie-estudos.ucdb.br/index.php/serie. Acesso em: 16 maio 2020.

\section{Como referenciar este artigo}

COSTA, Clara Corrêa da; GONÇALVES, Helenice Maia. Formação pedagógica no curso de pedagogia: indefinições e desafios. Revista on line de Política e Gestão Educacional, Araraquara, v. 24, n. 2, p. 631-649, maio/ago., 2020. e-ISSN: 1519-9029. DOI: https://doi.org/10.22633/rpge.v24i2.13772

Submetido em: 10/01/2020

Revisões requeridas: $20 / 02 / 2020$

Aprovado em: 25/03/20

Publicado em: 09/04/2020 